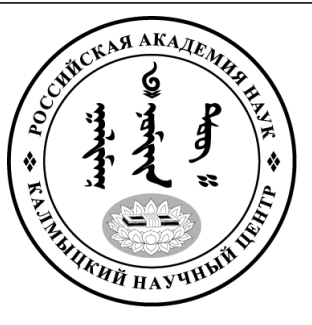

Published in the Russian Federation

Oriental Studies (Previous Name: Bulletin of the Kalmyk Institute

for Humanities of the Russian Academy of Sciences)

Has been issued as a journal since 2008

ISSN: 2619-0990; E-ISSN: 2619-1008

Is. 5, pp. $883-890,2019$

DOI: $10.22162 / 2619-0990-2019-45-5-883-890$

Journal homepage: https://kigiran.elpub.ru

УДК 930.2+294.321+ 39+811.512.37

\title{
Рукопись «История семи перерождений халхаских ноён-хутухт» из коллекции квартиры-музея Ц. Дамдинсурэна
}

\author{
Яна Дмитриевна Леман ${ }^{1,2}$ \\ ${ }^{1}$ Институт востоковедения РАН (д. 12, ул. Рождественка, 107031 Москва, Российская Федерация) \\ младший научный сотрудник \\ ${ }^{2}$ Институт классического Востока и античности НИУ «Высшая школа экономики» (д. 21/4, стр. 3, \\ Старая Басманная ул., 105066 Москва, Российская Федерация) \\ преподаватель \\ ORCID: 0000-0002-9812-4049. E-mail: yleman@mail.ru
}

\begin{abstract}
Аннотация. Цель. В статье рассматривается рукопись из коллекции квартиры-музея Ц. Дамдинсурэна в г. Улан-Баторе, являющаяся важным источником по биографии Равджи (1803-1856), известного монгольского поэта и религиозного деятеля. Материаль. Рукопись содержит краткие жизнеописания семи представителей линии перерождений халхаских ноён-хутухт, к которой относился Равджа, в том числе новые сведения о жизни непосредственного предшественника Равджи, действия которого привели к запрету дальнейших перерождений хутухт данной линии. Результаты. В статье выдвигается предположение об истории создания данного исторического и литературного памятника. Несмотря на свой небольшой объём, эта рукопись из собрания академика Ц. Дамдинсурэна представляет собой большой интерес для исследователей монгольской литературы, истории и религии. Приводятся транслитерация, перевод и факсимильные копии оригинала рукописи. Рукопись и её перевод впервые вводятся в научный оборот. Публикуемый документ является, по-видимому, одним из источников, которыми пользовался академик Ц. Дамдинсурэн при написании своей известной статьи «О пьесе „Лунная кукушка“». Долгое время эта статья являлась основным источником информации о халхаских ноён-хутухтах, поэтому возможность исследовать её происхождение представляется крайне ценной.

Ключевые слова: Монголия, буддизм, монгольская литература, рукопись, жизнеописание Для цитирования: Леман Я. Д. Рукопись «История семи перерождений халхаских ноён-хутухт» из коллекции квартиры-музея Ц. Дамдинсурэна. Oriental Studies. 2019; (5): 883-890. DOI: 10.22162/2619-0990-2019-45-5-883-890.
\end{abstract}

UDC 930.2+294.321+39+811.512.37

\section{'Noyon Khutagts of Khalkha: History of Seven Incarnations': a Manuscript from Ts. Damdinsuren Memorial House}

Yana D. Leman ${ }^{1,2}$

${ }^{1}$ Institute of Oriental Studies of the RAS (12, Rozhdestvenka St., 107031 Moscow, Russian Federation) Junior Research Associate 


\footnotetext{
${ }^{2}$ Institute for Oriental and Classical Studies, National Research University Higher School of Economics (21/4, bldg. 3, Staraya Basmannaya St., Moscow 105066, Russian Federation)

Lecturer

ORCID: 0000-0002-9812-4049.E-mail: yleman@mail.ru
}

\begin{abstract}
Goals. The article examines a manuscript from Ts. Damdinsuren Memorial House (Ulaanbaatar) which contains precious biographical data about Ravjaa (1803-1856), a renowned Mongolian poet and clergyman. Materials. The manuscript outlines biographies of seven Khalkha Noyon Khutagt incarnations - including that of Ravjaa - and provides an new insight into the life of Ravjaa's immediate predecessor whose activities had resulted in that any further reincarnations within the tulku line were officially banned. Results. The paper makes assumptions regarding circumstances that accompanied the creation of the historical and literary monument. Despite the text is short enough, the manuscript may be of great interest to researchers of Mongolian literature, history and religion. The work transliterates and translates the text, publishes a facsimile copy of the original manuscript, thus, introducing the latter into scientific discourse. The document seems to have served as a source the Academician Ts. Damdinsuren had made use of when writing his famous article 'About the Moon Cuckoo Play'. For a long time the latter remained the only text available dealing with Khalkha Noyon Khutagts, and now there is an opportunity to examine its original source materials.

Keywords: Mongolia, Buddhism, Mongolian literature, manuscript, biography

For citation: Leman Ya. D. 'Noyon Khutagts of Khalkha: History of Seven Incarnations': a Manuscript from Ts. Damdinsuren Memorial House. Oriental Studies. 2019;(5): 883-890. DOI: 10.22162/2619-0990-2019-45-5-883-890.
\end{abstract}

\title{
है
}

\section{Введение}

Равджа (1803-1856), иначе называемый Дандзан-Равджа или $\mathrm{V}$ Гобийский ноён-хутухта, часто привлекает внимание исследователей монгольской литературы и буддизма. Будучи монахом-перерожденцем - хутухтой, он был широко известен как поэт, автор не только стихотворных поучений в духе буддийской проповеди, но и первых в истории монгольской литературы образцов любовной лирики. Он входил в линию перерождений, именовавшуюся в монгольских исторических источниках как «халхаские ноён-хутухты», реже - «гобийские ноён-хутухты» или «гневные ноён-хутухты».

В Монголии первый ноён-хутухта появился в 1622 г. [Altangerel, Khatanbaatar 2009: 22], а до того, согласно традиции, перерождался более 30 раз в Тибете и Индии. До революции 1921 г. в Монголии родилось семь ноён-хутухт, пятым из которых и был Равджа. Интерес представляет не только его поэзия, но и жизнь и деятельность в целом: он был просветителем, создал театр и шко- лу для бедных в основанном им монастыре, был известен как целитель и художник. В то же время его фигуру можно назвать противоречивой - он конфликтовал с высшим ургинским духовенством, имел репутацию пьяницы и «любителя женщин». Это объясняется тем, что Равджа не ограничивался практиками основной для Монголии школы гелугпа, предполагающей соблюдение кодекса строгих монашеских правил, но имел и различные сакьяские и, возможно, ньинмапаские тантрические посвящения, поэтому его поведение с «желтошапочной ${ }^{1}$ » точки зрения могло казаться шокирующим.

\section{Основная часть}

Известно, что существует несколько видов биографий Равджи: «обширное» жизнеописание, краткое жизнеописание, история перерождений халхаских ноён-хутухт. О нем упоминают монгольские летописи, много рассказов о совершенных им чудесах,

\footnotetext{
1 Желтошапочниками в Монголии называют буддистов, принадлежащих к школе гелуг, за характерный головной убор.
} 
передававшихся изустно наподобие преданий и в дальнейшем записанных исследователями. Из этих материалов опубликованы, не считая летописей [Erdeni-yin erike 2007], лишь сборники преданий о нем [Цэрэнпил 1995] и краткое жизнеописание [Лхагвасүрэн 1993: 151-167; Хүрэлбаатар 2006: 311-329].

Развёрнутый вариант биографии считается утраченным, хотя существуют свидетельства нескольких очевидцев о том, что они видели ${ }^{2}$ экземпляры этой книги ещё в середине ХХ в. [Хүрэлбаатар 2006: 238].

На различные варианты истории семи перерождений часто ссылаются монгольские учёные, крупные специалисты по творчеству Равджи (Г. Лхагвасурэн, Л. Хурэлбаатар), однако встретить этот текст в печатном виде практически невозможно, как и найти его версию в большинстве каталогов [Bawden 1969; Farquhar 1955; Heissig 1954; Heissig, Bawden 1971; Poppe, Hurvitz, Okada 1964; Uspensky 1999; Сазыкин 1988].

Приводя сведения касательно событий из жизни Равджи, многие авторы опираются на одну и ту же статью Ц. Дамдинсурэна: «О пьесе „Лунная кукушка“» (монг. «Саран хөхөөний» жүжгийн учир) [Равжаа 1962; Дамдинсүрэн 1984: 68-107]. В ней учёный рассказывает не только о пьесе, вынесенной в заглавие статьи, о её тибетских истоках, о том, с какими трудностями столкнулись исследователи в попытках собрать все её десять тетрадей, но и о самом хутухте - о его творчестве в целом и о его биографии. Именно здесь встречается наиболее раннее в научной литературе упоминание о короткой и развернутой биографиях Равджи. Ц. Дамдинсурэн подробно описывает, какие версии короткой биографии ему встречались, упоминает историю семи перерождений и на их основе даёт собственное, достаточно сжатое, изложение основных событий жизни Равджи. Сами тексты биографий так и не были опубликованы.

Автор одной из самых полных монографий о Равдже, Л. Хурэлбаатар, касается в своей работе вопросов его творчества и биографии, а также проблем, связанных с

2 По мнению С. Ю. Неклюдова, выраженного в ходе устной дискуссии, эти слухи могут быть составной частью комплекса мифов и легенд, традиционно возникающих вокруг фигур, подобных Равдже. их научным изучением. Ему приходилось постоянно ссылаться на статью Ц. Дамдинсурэна о «Лунной кукушке» как на один из основных источников информации об имеющихся биографиях Ноён-хутухты. Чтобы сравнить те тексты, что находились в его распоряжении, с вариантами, использованными Ц. Дамдинсурэном, он приводит цитаты из статьи последнего. Таким способом он сопоставляет версию короткой биографии, обнаруженную им в Монгольской Национальной библиотеке и опубликованную в его книге [Хүрэлбаатар 2006: 400-415], с той, которой пользовался Ц. Дамдинсурэн, и приходит к выводу, что это разные варианты.

Когда речь заходит об истории всех перерождений ноён-хутухт, Л. Хурэлбаатар опирается на тибетоязычные источники ${ }^{3}$. Из источников на монгольском языке ему была доступна летопись «Драгоценные четки» (монг. Erdeni-yin erike), составленная в середине XIX в. Галдан-туслагчи, и «История Гневных Гобийских ноён-хутухт из хошуна халхаского Мэргэн-вана» (монг. Qalq-a-yin mergen vang-yin qosiyun-u yobi-

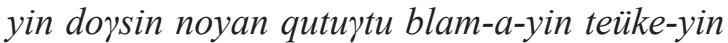
tobči medegdekün inü engde orosibai), библиографических данных о которой он, к сожалению, не указывает.

«История ноён-хутухт» представляет собой, по словам Л. Хурэлбаатара, очень краткое описание жизни семи перерождений. Как и в тексте, на который ссылается в своей статье Ц. Дамидинсурэн, «Семь перерождений ноён-хутухт» (монг. noyan

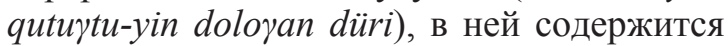
лишь минимальный набор сведений: когда человек родился, был признан хутухтой, умер. Используя выдержки из него, приводимые в статье, Л. Хурэлбаатар привлекает и этот источник в своей работе.

В 2018 г. совместными усилиями монгольских и российских учёных было подготовлено второе, переработанное и расширенное, издание каталога собрания квартиры-музея Ц. Дамдинсурэна [Билгуудэй, Отгонбаатар, Цендина 2018: 181-182]. В каталоге отражены две группы текстов, относящихся к ноён-хутухтам:

${ }^{3}$ (1) No yin hu thag thu'i sku 'phring rim par rgyud pa ni; (2) sNgags ram pa chos rje'i No yin huthag thu'i bla ma'i sku 'phreng rim par rgyud pa'i [Хүрэлбаатар 2006: 254]. Библиографические сведения не приведены. 
История перерождений ноён-хутухт:

206. (923) Ш3-142 (МH-1100);

207. (924) Ш3-141 (MH-1099);

208. (925) Ш3-124 (МH-1081).

2) Жизнеописания Четвёртого ноён-хутухты:

209. (926) A2-127 (MH-879);

210. (911) Ш3-69 (МН-1025).

Ознакомившись с первой группой текстов, можно с большой вероятностью предположить, что именно этими материалами пользовался академик Ц. Дамдинсурэн при подготовке своей статьи, послужившей источником уникальной информации для многих авторов. Три номера, 206, 207 и 208, в действительности включают пять текстов, четыре из которых являются описанием

206. (923) Ш3-142 (MH-1100)

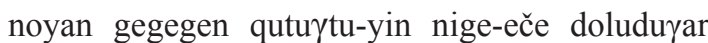
düri nögöd-ün tobči teüke

nigedüger blam-a anu

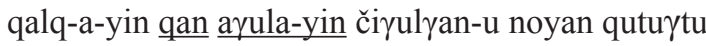
jamiyangodubčimču aqsan-u u $\gamma$ ekilečü qubiluqsan-u üi-e ner-e čolu-yi bayičayabasu

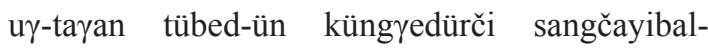
sang-un angqan-a uda $\gamma$-a qubilyan yaruqsan-u qoyin-a qalqa-a-yin sonom dayičing qungtay-

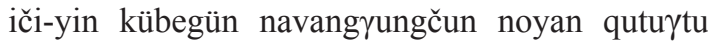
bölüge

qoyaduyar blam-a amu .

qoyin-a tüšiyetü qan ayimaq-un dančanyaringbal aqsan-u qoši mekü kümün-ü ger-tü jamyanqdangjan qubilyan yaruqsan

qoyin-a čering-ün kereg-dür jarin tabun

mori-bar küčü bariqsan-dur

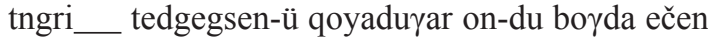

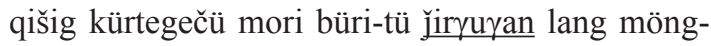
gö-ber šangnačuqui

Как можно видеть на этом небольшом фрагменте, тексты совпадают практически дословно, кое-где расходясь в грамматических формах и некоторых фактографических элементах (как количество лан серебра, полученное за лошадей, или звание «бей- жизни семи перерождений ноён-хутухт, а пятый — «короткой» биографией Пятого ноён-хутухты Дандзан-Равджи. Некоторые листы сохранили пометки и правку Ц. Дамдинсурэна.

Из четырех «Историй перерождений» две являются копиями одного текста - одна копия рукописная, другая набрана на монгольской старописьменной печатной машинке. Ещё один текст очень близок к этим двум, но имеет некоторые расхождения. Последний текст значительно отличается от остальных трёх вариантов, хотя также содержит краткое жизнеописание семи перерождений ноён-хутухт.

Рассмотрим варианты, имеющие небольшие отличия.

208. (925)Ш3-124 (MH-1081)

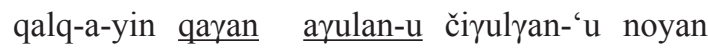

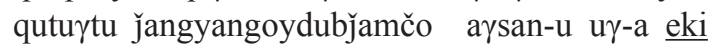
qubilaysan üy-e ner-e čolu-

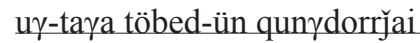

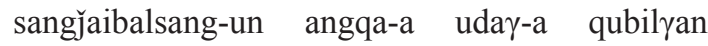
yaryasan-u ___ qalaq-a-yin sonom dayičing qungtayiji-yin kübegün navangongčo $\gamma$ noyan quturtu bölüge

qoyin-a tüšiyetü qan ayimay-un beyise danjinyaringpil aysan-u qošijun-u qar[aju]

süngdür kemekü kümün-ü ger-tü jamyangdangjanyin qubilyan $\gamma a r[u \gamma s a n]$ qoyin-a čereg-ün keregdur jiran tabun mori-bar küčü bariqysan-dur tngri-yin tedkügsen-ü qoyaduyar on-du boyda ečin kešig kürtege üü mori büri-dü arbayad lang mönggü__šangnajuqui

се», опущенное в одной из версий). Можно предположить, что тексты восходят к одному оригиналу, а различия появились позднее при его переписывании. Также в тексте № 208 отсутствует название. Различается и подход к орфографии: переписчик текста из 
№ 206 был более склонен прописывать все буквы в словах и ставить диакритику там, где это принято.

Таким образом, можно заключить, что в собрании квартиры-музея имеется два варианта «Истории семи перерождений», один из которых представлен в трёх версиях, восходящих, предположительно, к одному исходному тексту.

Из этих трёх списков наибольший интерес представляет рукопись под номером 208. (925) Ш3-124 (МН-1081), как наиболее архаичная. В отличие от двух других, один из которых набран на монгольской старописьменной пишущей машинке, а другой записан карандашом, эта «История перерождений» выполнена кистью, чёрными чернилами, на китайской бумаге, сложенной гармошкой. Объём текста составляет 10 страниц (5 л.), размером 9,5 на 26,5 см, по 6 строк на каждой. Стиль письма тяготеет к скорописи, «зубчики» часто не прописываются, имеются ошибки и описки.

Любопытна композиция этого текста. Вводная фраза даёт понять, что история перерождений халхаских ноён-хутухт будет рассмотрена в связи с личностью четвёртого из них, Джамьян-Ойдов-Джамцо. Истории всех хутухт до него описаны очень кратко, приводятся сведения о времени и месте рождения, родителях, времени возведения на престол и смерти. Четвертому хутухте уделено больше внимания, появляются дополнительные данные. После этого оставшиеся хутухты снова лишь скупо перечисляются.

Краткое перечисление перерождений крупного религиозного деятеля являлось обычной практикой, можно вспомнить хотя бы списки перерождений Джебдзун-Дамба-хутухты или Нейджи-тойна. Однако текст позволяет предположить, что составитель рассматриваемой «Истории перерождений ноён-хутухт» воспользовался для этой цели бывшими в его распоряжении документами, возможно, административного характера, относящимися к Четвертому ноён-хутухте, Джамьян-Ойдов-Джамцо. Основания для такого утверждения нам дают два обстоятельства. Хотя в тексте отражены все семь перерождений, жившие в Монголии до революции 1921 г., он открывается словами: «Если изучать происхождение, время первого воплощения, имя и титул халхаско- го ноён-хутухты Джамьян-Ойдов-Джамцо из чулгана Хан-ула...». Джамьян-Ойдов-Джамцо, четвёртое перерождение, имеет в своей биографии (как известно из других источников, например, из летописи «Драгоценные четки» [Erdeni-yin erike 2007]) эпизод, привлекший к нему внимание властей. Этот хутухта заколол ножом одного монаха, после чего лишился сана, шабинаров (т. е. приписанных к нему скотоводов, обязанных его содержать) и права перерождаться. Когда перечисление перерождений доходит до четвертого, в повествование, до того называвшее всех героев в третьем лице, вкрапляется речь от первого лица: «Я, Джамьян-Ойдов-Джамцо из рода Борджигин, кости Киют, родился в год коровы, возраст - 25 лет, титул - ноён-хутухта. Мой отец - управитель (дзасаг) Ринчендордж. Всего перерождался четыре раза. Мое кочевье - три богатых места: Аю-кача гоби, Бадзасаруга и Джалчи Хугдэрэсу...». Затем снова в третьем лице: «Этого ноён-хутхту Джамьян-Ойдов-Джамцо лишили звания хутухты из-за совершенного им проступка».

Вероятно, Джамьян-Ойдов-Джамцо приходилось писать докладные или объяснительные записки в процессе разбирательства по его делу. Возможно, что и историю четырёх перерождений изначально ему или его окружению пришлось составить по этой же причине, а затем её продолжили, внеся последние актуальные данные о дальнейших перерождениях.

\section{Заключение}

Таким образом и появилась биография семи перерождений ноён-хутухт. Обычно жизнеописания религиозных деятелей Монголии, кроме самых ранних, составлялись на тибетском языке. В XVIII в. на монгольском писались только биографии Джебзундамба-хутухт. Вероятно, это связано с тем, что первый Джебзун-Дамба, Ундур-гэгэн, был символом национального развития Монголии, его деятельность имела особое значение не только для буддизма и буддийской церкви, но и, прежде всего, для Монголии, для ее политической и культурной истории. Это дает основание предположить, что Равджа, а вслед за ним все остальные халхаские ноён-хутухты, как и перерождения Джебзундамбы, рассматривались носителями традиции как выразители национального 
духа монголов. С переводом этого текста мы и предлагаем ознакомиться читателю.

\section{История семи перерождений хал- хаских ноён-хутухт ${ }^{4}$}

[1] Если изучать происхождение, время первого воплощения, имя и титул халхаского ноён-хутухты Джамьян-Ойдов-Джамцо из чулгана Хан-ула, [то можно увидеть, что] впервые тибетский Гунгадордж Санджай-Балсанг переродился сыном халхаского хунтайджи Соном-Дайчина, [которого назвали] Наван-Гончиг. После этого хубилган переродился в хошуне бейсе ДанзданЯринпила Тушетуханского аймака, [2] в семье человека по имени Сундэр [и получил имя] Джамьян-Дандзан. Когда он поддержал военное предприятие, дав 65 лошадей, на втором году правления императора Тэнгэрийн-Тэтгэсэн (1737) Богдо-эдзэн дал ему благословение и наградил примерно десятком лан серебра за каждую лошадь.

После смерти [Джамьян-Дандзана], на восьмой год правления императора Тэнгрийн-Тэтгэсэн (1743), хубилган переродился в семье управителя Тушетуханского аймака Цэдэна. Затем, на 24-й год правления императора Тэнгэрийн-Тэтгэсэн (1759), по указанию эфу Санджай-Дорджа ноён-хутухту Лубсан-Джамьян-Дандзана наградили печатью управителя и одним сомоном шабинаров, которые образовали хошун. После того, как на 32-й год правления императора Тэнгэрийн-Тэтгэсэн (1768) [4] ноён-хутухта Лубсан-Джамьян-Дандзан скончался, по указу [императора] был отправлен сановник, который передал благословение [императора], дары, серебряную мандалу, хадаки и воскурения.

После этого хубилган ноён-хутухты переродился в семье управителя Тушетуханского аймака Ринчен-Дорджа и на 37-й год правления императора Тэнгэрийн-Тэтгэсэн (1771), [5] по указанию эфу Санджай-Дорджа сын Ринчен-Дорджа получил тех шабинаров. На 45-й год правления императора Тэнгэрийн-Тэтгэсэн (1780), когда я, ноён-хутухта Джамьян-Ойдов-Джамцо, прибыл к небесному императору с изъявлением почтения, я получил благословение, был приглашен принять участие в пирше-

${ }^{4}$ Из коллекции дома-музея Ц. Дамдинсурэна: № 208. (925) Ш3-124 (МН-1081). стве [6] и был награжден шёлковой материей. C тех пор каждый год в столицу посылался человек с письмом в великую управу, выражающим почтение [императору], и он возвращался с дарами.

Я, Джамьян-Ойдов-Джамцо из рода Борджигин, кости Киют, родился в год коровы, возраст - 25 лет, титул - [7] ноён-хутухта. Мой отец - управитель Ринчен-Дордж. Всего перерождался четыре раза. Мое кочевье - три богатых места: Аю-кача гоби, Бадзасаруга и Джалчи Хугдэрэсу, где я проживаю вместе с хошуном управителя дзюнвана Дорджи-Джава.

Этого ноён-хутухту Джамьян-ОйдовДжамцо лишили звания хутухты из-за совершенного им проступка, а шабинаров сомона Улуа прибавили для управления к хошуну того вана Дорджи-Джава.

[8] После того, как Джамьян-Ойдов-Джамцо скончался, на 8-й год правления императора Сайшалт-Еролта (1803) в хошуне восточно-сунитского вана Шилэнгольского чулгана в семье Дулдуйта родился хубилган, которого назвали перерождением Аграмба-цорджи. В возрасте 8 лет он получил шабинаров.

После того, как аграмба-цорджи Дандзан-Рабчжай на 6-й год правления императора Тугэмэл-Элбэгта (1856) [9] скончался, в том же году в семье отца Джебдзун-Дамба-хутухты, тибетского подданного, тушэту-гуна Мягмара родился хубилган. В возрасте 14 лет хубилгану Лубсан-Дондову передали тот самый хошун, сомон, монастырь и шабинаров для управления ими. [10] Хубилган Лубсан-Дондов скончался в первый год правления императора Бадрагулт-Тура (1875).

После чего родившийся в семье шабинара этого хутухты, военачальника Шарху, хубилган Агван-Лубсан-Дамби-Джалцан на 5-й год правления Бадрагулт-Тура (1879) в возрасте пяти лет девятого числа восьмого месяца был возведен на престол и получил этот сомон, земли и монастырь.

Транслитерация: [1] qalq-a-yin

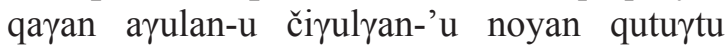
jangyangoydubjamčo a $\gamma_{s a n-u} u \gamma$-a eki qubilaysan üy-e ner-e čolu-a bayičayabasu u $\gamma-$

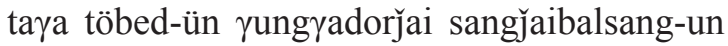

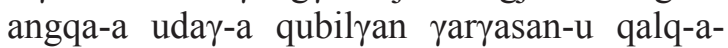
yin sonom dayičing qungtayiǰi-yin kübegün 
navangongčo $\gamma$ noyan qutu $\gamma$ tu bölüge. qoyin-a tüšiyetü qan ayima $\gamma$-un beyise danǰinyaringpil

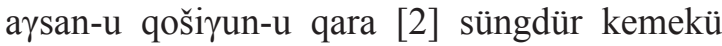
kümün-ü ger-tü jamyangdangjan-yin qubilyan yar[uүsan] qoyin-a čereg-ün kereg-tur jiran tabun mori-bar küčü bariysan-dur tngri-yin tetgügsen-ü qoyaduyar on-du boyda ejin kešig kürtegejü mori büri-dü arbayad lang mönggü šangnaǰuqui. tegünü-yi ǰangči qalaysan qoyin-a tngri tetgügsen-ü nayimaduyar on-du noyan qutuytu-yin qubilyan tüšiyetü [3] qayan

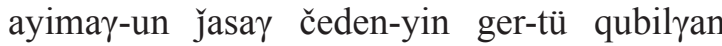
yaruysan qoyin-a tngri-yin tetgüsen-ü qorin dürbedüger on-du jangǰu efu sangjayidorǰi-

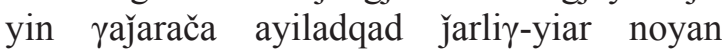

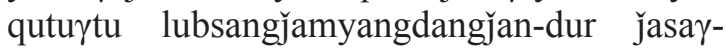

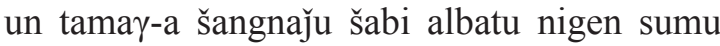

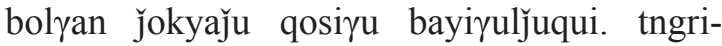
yin tetgügsen-ü yučin qoyaduyar [4] on-du noyan qutu $\gamma$ tu lubsangjamyangdangjan-u

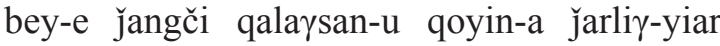
sayid yaryaču kešig kürtegejü buyan kürgejü mönggün mangdal ba qada küǰi seltes kürgen

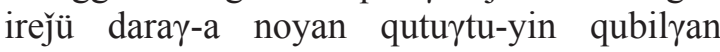
tüšiyetü qana ayimaq-un ǰasaq eringčingdorǰiyin ger-tür qubilyan yaruysan ni tngri-yin

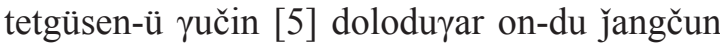
efu sangjaydorj̄i-yin yaǰarča ulamǰilan

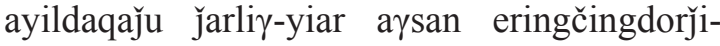
yin kübegün-i u $\gamma$ šabinar-tu neyilegüljügün. tngri tetgüsen-ü döčin tabuduyar on-du noyan qutuүtu jamyangoyidobjamču bi tngri-yin

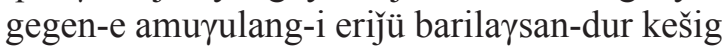

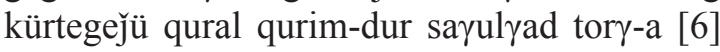

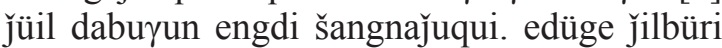
kümün irejü neyislel qota-dur ilegejü yeke

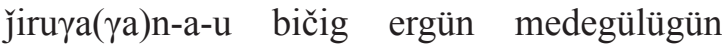

\section{Литература}

Сазыкин 1988 - Сазыкин А. Г. Каталог монгольских рукописей и ксилографов Института востоковедения Академии наук СССР Т. І. М.: Наука, 1988. 508 с.

Билгуудэй, Отгонбаатар, Цендина 2018 - БилгүҮдэй Г., Отгонбаатар Р., Цендина А. Ц. Дамдинсүрэнгийн гэр музейн монгол ном судрын бүртгэл (= Каталог монгольских рукописей и ксилографов из квартиры-музея Ц. Дамдинсурэна). Улаанбаатар: Соёмбо принтинг, 2018. 620 х.

Дамдинсүрэн 1984 - Дамдинсүрэн Ц. Монголын уран зохиолын өв уламжлалын асуудалд (= К вопросу о монгольском литературном degedü-yin amuүulang-i erijü bileg bariqsayar iregsen amui. ǰamyangoyidobǰamču minu yesü keyud obo $\gamma$ borjigin üker jil-tei qorin tabun nasutai čolu-a [7] noyan qutuytu minu ečig ǰasay eringčingdorji bolumui. bügede dörben qubaljuqui. nuta yobi bajaasaruga jalči kügderesu yurban bayan jerge yaǰar-ud-dur jasay törü-yin qayiun vang

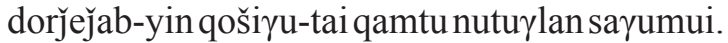
ene noyan qutuүtu jamyangoyidobjamču kereg-yin učir-yiar qutuytu-ača bayilyaču uulu-a sümü šabinar-i mön [8] vang dorǰejabyin qošizun-dur qabsuryaju jakiraysan qoyin-a jamyangoyidubjamču-yi jangči qalaysan qoyin-a sayišiyaltu erügeltü yin-e

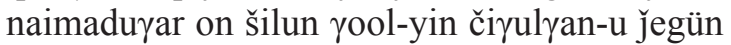
sünid vang-un qošiju-nu duludui-tu-yin gertür qubilyan yaruүsan-i agramba čorji-yin qubilyan kemen neredüjü naiman nasun-dur u $\gamma$ šabinar-tur neyilegülün jalajuqui. agramba čorǰi danǰanrabǰay-a tügemel elbegtü- [9] yin

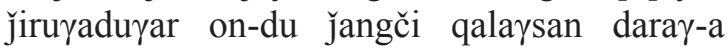
mön on-du geleng ǰbčungdamba quturtu-yin ečige töbid-ün qariyatu udu-a tüšiyet-ün güngün jerge mimar-yin ger-tü qubilyan yaruysan qoyin-a qubilyan lubsangdondob-i arban dörben nasun-dur uul-a qoši $\gamma$ sümü oron keyidün yaǰara u $\gamma$ šabinar-dur neyilegülün jalajuqui. qubilyan lubsangdongdob baduruyalu-tu [10] törü-yin terigün on-du jangči qalaysan

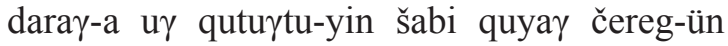
daruү-a šarkuu-yin ger-tür qubilyan yaruqsan-u badaryultu törü-yin tabuduyar on-du qubilyan aүvanglubsangdambiyj̆alčan-i tabun nasundur uul-a sümü oron keyid-ün yaǰar-a naiman sarayin šineje yisün-dür širen-e sayulyan jalačuqui

наследии). Улаанбаатар: Шинжлэх ухааны академийн хэвлэл, 1984. 285 х.

Лхагвасүрэн 1993 - Лхагвасүрэн Г. Ноён хутагт Данзанравжаа (= Ноён-хутухта Дандзанравджа). Улаанбаатар: Засгийн газрын хэвлэх үйлдвэр, 1993. 168 х.

Равжаа 1962 - Равжаа Д. Саран хөхөөний намтар (= Биография Лунной кукушки). Улаанбаатар: Эрдэм Шинжилгээний хэвлэл, 1962. $214 \mathrm{x}$.

Хүрэлбаатар 2006 - Хүрэлбаатар Л. Аварга могойн зулайн чандмань (= Драгоценность на макушке Аварга-могой). Улаанбаатар: Admon, 2006. $415 \mathrm{x}$. 
Цэрэнпил 1995 - Цэрэнпил Ш. Хутагтын тухай хууч (= Легенды о хутухте). Улаанбаатар: Улсын стандартын хэвлэх үйлвдэр, 1995 $48 \mathrm{x}$.

Altangerel, Khatanbaatar 2009 - Altangerel Z., Khatanbaatar Ch. A Brief History of Khamar Monastery. Ulaanbaatar: Tavan Dokhio, 2009. $68 \mathrm{p}$.

Erdeni-yin erike 2007 — Erdeni-yin erike kemekü teüke bolai (= История под названием «Драгоценные чётки»). Transcr. J. Gerelbadrakh, ed. Yo. Janchiv. Ulaanbaatar: Admon, 2007. $999 \mathrm{x}$.

Bawden 1969 - David L. Snellgrove, C. R. Bawden. The Chester Beatty Library: a catalogue of the Tibetan collection and a catalogue of the Mongolian collection. 109 p. Dublin: Hodges, Figgis and Co., Ltd., 1969. 84 p.

Farquhar 1955 - David M. Farquhar. A Description of the Mongolian Manuscripts and Xylographs in Washington, D. C. // Central Asiatic Journal, Vol. 1. No. 3. 1955. Pp. 161-218.

Heissig 1954 - Heissig $W$. Die Pekinger lamaistischen Blockdrucke in mongolischer $\mathrm{Li}^{-}$ teraturgeschichte. (Göttinger Asiatische Forschungen, Bd. 2.) Wiesbaden: Otto Harrassowitz, 1954. XV + $220 \mathrm{~S}$.; mit $18 \mathrm{Abb}$.

Heissig, Bawden 1971 - Heissig W., Bawden Ch. Catalogue of Mongol books, manuscripts and xylographs. (Catalogue of Oriental manuscripts, xylographs etc. in Danish collections, Vol. 3). Copenhagen: Royal Library, 1971. 305 p.

Poppe, Hurvitz, Okada 1964 - Poppe N., Hurvitz L., and Okada H. Catalogue of the ManchuMongol Section of the Toyo Bunko. Tokyo: The Toyo Bunko and the University of Washington Press, 1964. 387 p.

Uspensky 1999 - Catalogue of the Mongolian Manuscripts and Xylographs in the St. Petersburg State University Library / compiled by Vladimir L. Uspensky with assistance from Osami Inoue; Tatsuo Nakami (ed.). Tokyo: Institute for the Study of Languages and Cultures of Asia and Africa, 1999. 186 p.

\section{References}

[Erdeni-yin erike kemekü teüke bolai: The Precious Rosary]. J. Gerelbadrakh (transcr.), Yo. Janchiv (ed.). Ulaanbaatar: Admon, 2007. 999 p. (In Mong.)

Altangerel Z., Khatanbaatar Ch. A Brief History of Khamar Monastery. Ulaanbaatar: Tavan Dokhio, 2009. 68 p. (In Eng.)
Bilgüüdey G., Otgonbaatar R., Tsendina A. Ts. [Ts. Damdinsuren Memorial House: Catalogue of Mongolian Manuscripts and Xylographs]. Ulaanbaatar: Soembo Printing, 2018. 620 p. (In Mong.)

Catalogue of the Mongolian Manuscripts and Xylographs in the St. Petersburg State University Library. V. L. Uspensky, O. Inoue (comps.), Tatsuo Nakami (ed.). Tokyo: Institute for the Study of Languages and Cultures of Asia and Africa, 1999. 186 p. (In Eng.)

Damdinsuren Ts. [Mongolian Literary Heritage Revisited]. Ulaanbaatar: Mongolian Academy of Sciences, 1984. 285 p. (In Mong.)

Farquhar D. M.. A description of the Mongolian manuscripts and xylographs in Washington, D. C. Central Asiatic Journal. 1955. Vol. 1. No. 3. Pp. 161-218. (In Eng.)

Heissig W. Die Pekinger lamaistischen Blockdrucke in mongolischer Literaturgeschichte [Beijing Lamaist Publications in Mongolia's Literary History]. (Göttinger Asiatische Forschungen, Bd. 2.) Wiesbaden: Otto Harrassowitz, 1954. $\mathrm{XV}+220$ p. (In Germ.)

Heissig W., Bawden C. Catalogue of Mongol Books, Manuscripts and Xylographs. (Catalogue of Oriental Manuscripts, Xylographs etc. in Danish Collections, Vol.3). Copenhagen: Royal Library, 1971. 305 p. (In Eng.)

Khürelbaatar L. [The Gem of the Top of Avarga Mogoy's Head]. Ulaanbaatar: Admon, 2006. 415 p. (In Mong.)

Lkhagvasüren G. [Danzanravjaa Noyon Khutagt]. Ulaanbaatar: State Publ. House, 1993. 168 p. (In Mong.)

Poppe N., Hurvitz L., Okada H. Catalogue of the Manchu-Mongol Section of the Toyo Bunko. Tokyo: The Toyo Bunko and the University of Washington Press, 1964. 387 p. (In Eng.)

Ravjaa D. [Biography of the Moon Cuckoo]. Ulaanbaatar: Erdem, 1962. 214 p. (In Mong.)

Sazykin A. G. [Institute of Oriental Studies, USSR Academy of Sciences: Catalogue of Mongolian Manuscripts and Xylographs]. Vol. I. Moscow: Nauka, 1988. 508 p. (In Russ.)

Snellgrove D. L., Bawden C. R. The Chester Beatty Library: a Catalogue of the Tibetan Collection and the Mongolian Collection. Dublin: Hodges, Figgis and Co. Ltd., 1969. 109 p. (In Eng.)

Tserenpil Sh. [Legends about the Khutagt]. Ulaanbaatar: State Standard Publ., 1995. 48 p. (In Mong.) 